\title{
The Carbonate-catalyzed Transesterification of Sunflower Oil for Biodiesel Production: in situ Monitoring and Density Functional Theory Calculations
}

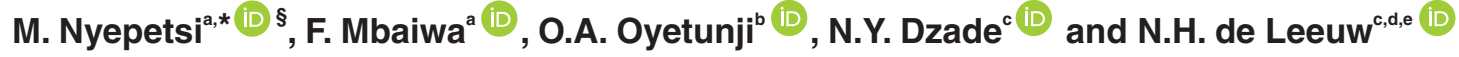 \\ ${ }^{a}$ Department of Chemical and Forensic Sciences, Botswana International University of Science and Technology (BIUST), Palapye, Botswana. \\ ${ }^{b}$ Department of Chemistry, University of Botswana, Gaborone, Botswana. \\ ${ }^{c}$ School of Chemistry, Cardiff University, Main Building, Park Place, Cardiff CF10 3AT, United Kingdom. \\ ${ }^{d}$ Department of Earth Sciences, Utrecht University, Princetonlaan 8a, 3584 CB Utrecht, Netherlands. \\ ${ }^{e}$ School of Chemistry, University of Leeds, Leeds LS2 9JT, United Kingdom. \\ Received 27 February 2020, revised 23 July 2020, accepted 27 July 2020.
}

\begin{abstract}
Biodiesel has emerged as a promising alternative fuel to replace dwindling fossil-based resources, particularly in view of its added environmental merit of reducing additional air pollution. Its specific attraction stems from the similarity of its physical properties to fossil fuel-derived diesel. Although the production of biodiesel is a relatively straightforward process, reaction progress monitoring and product analysis require costly specialist equipment, such as gas chromatography and mass spectrometry. In this study, we investigate the use of $\mathrm{pH}$ in monitoring the progress of carbonate-catalyzed transesterification reactions. Specifically, we focus on potassium and sodium carbonates and sunflower oil. Our results are consistent with the results obtained by other studies using different methods of monitoring. To test the generality of the method, $\mathrm{pH}$ measurements were also used to monitor the progress of the potassium carbonate transesterification reaction in the presence of added water, glycerol and gamma-valerolactone (GVL). The obtained results are as expected, with a limited amount of water increasing the transesterification rate; glycerol slowing the reaction slightly in accord with Le Chatellier's principles; and GVL increasing the rate due to co-solvent effects. Atomic-level insights into the adsorption mechanism of methanol and water on the (001) surfaces of $\mathrm{Na}_{2} \mathrm{CO}_{3}$ and $\mathrm{K}_{2} \mathrm{CO}_{3}$ catalysts are provided by first-principles DFT calculations, which explain the increase in transesterification reaction rate upon the addition of water.
\end{abstract}

KEYWORDS

Transesterification, pH monitoring, biodiesel, Density Functional Theory ( DFT), co-solvent.

\section{Introduction}

Biodiesel has begun to emerge as a viable alternative fuel to replace dwindling fossil-based resources. Biodiesel is a fuel based on vegetable oil or animal fat, which consists of long-chain alkyl (methyl, ethyl or propyl) esters. ${ }^{1,2}$ Besides being renewable, biodiesel is attractive as a fuel because it releases fewer air pollutants per net energy than fossil fuels, and it is non-toxic, bio-degradable and has high energy efficiency. It also has a high cetane number and, unlike petroleum diesel, it contains no aromatics or sulphur. ${ }^{3-5}$ These characteristics reduce the emission of pollutants, such as carbon monoxide, sulphur dioxide and hydrocarbons, as are found in the exhaust gases of petroleum-based diesel. The ester molecule has an oxygen atom which makes it efficient in combustion, resulting in less carbon monoxide being produced. The ester group also makes biodiesel biodegradable.

Transesterification is the most common method of converting animal fats and plant oils to biodiesel. In this process, animal fats or plant oils are made to react with a short-chain alcohol (methanol, ethanol or propanol) in the presence of a catalyst to form alkyl esters, with glycerol produced as by-products of the reaction. Bases such as sodium or potassium hydroxides or metal ethoxides are used as catalysts for the transesterification process,

* To whom correspondence should be addressed. E-mail: nyepetsim@biust.ac.bw where a base reacts with alcohol to produce alkoxides, which in turn react with the glyceride to form fatty acid methyl esters (FAME) and glycerol. The advantage of using $\mathrm{NaOH} / \mathrm{KOH}$ is that they speed up the reaction, achieving $97 \%$ conversions in less than one hour at low temperatures of $50-70{ }^{\circ} \mathrm{C} .{ }^{6-9}$ The major problem is that water is produced as a by-product; this complicates the process as it results in the hydrolysis of FAME to form soap, which causes a decrease in the percentage yield of biodiesel, whereas a lot of time and energy is spent on the recovery of glycerol at the end of the reaction. Potassium carbonate, sodium carbonate, boiler ashes and refinery waste ashes of fibres, shell, and husks have been used as base catalysts to produce very good yields of FAME. ${ }^{10}$ The use of carbonates reduces the formation of soap because the carbonate reaction results in the formation of bicarbonates instead of water, which do not hydrolyze the esters. ${ }^{6,10}$

The production of biodiesel involves heating the feedstock and alcohols to certain temperatures, adding catalysts and agitating the mixture using stirrers until the reaction is completed. Several techniques have been developed to monitor the progress of the transesterification process, e.g. gas chromatography (GC), ${ }^{11}$ high-performance liquid chromatography (HPLC), ${ }^{12}$ gel permeation chromatography (GPC) ${ }^{13}$ and nuclear magnetic resonance (NMR). ${ }^{14}$ These methods require timeconsuming sample preparation techniques and are often used 
for offline monitoring. It is also difficult to monitor fast and reversible reactions like transesterification. ${ }^{15}$

Recent efforts have focussed on the development of simple, cheap and non-invasive techniques for the in situ monitoring of biodiesel production, for example, the non-invasive near infra-red (NIR) method developed by Knothe et al., ${ }^{16}$ which was shown to be a robust approach capable of predicting the properties of biodiesel, such as kinematic viscosity and boiling points. They used a peak at $6050 \mathrm{~cm}^{-1}$ to show the formation of methyl esters, whereas partial least squares (PLS) fitting was used to calibrate the area under the peak to quantify the products. Limitations associated with this method included overlap of peaks of interest with other peaks, e.g. those of methanol. In addition, some of the peaks were not well resolved, and the method may lead to erroneous interpretation of the results. ${ }^{16}$

Another non-invasive monitoring technique was developed by De Boni et al., ${ }^{15}$ where laser light is used to study the changes in the refractive index of the reaction medium as the reaction progresses. The plots of resistance against time showed various regions that are characteristic of the different stages of the reaction. The first region is often assigned to the homogenization stage, which is characterized by a high degree of optical activity. The second region, characterized by a reduction in the refractive index, is due to the presence of reversible reactions, with the third region representing the state of equilibrium, characterized by the graph levelling off. The method is sensitive to the chemical composition of the reaction mixtures and impurities easily lead to erroneous data.

Another study has utilized an acoustic wave solid-state viscometer to carry out in situ measurements of viscosity during transesterification. ${ }^{17}$ The experiments were done at benchtop scale and in a pilot plant. The progress of the reaction was indicated by the decrease in viscosity of the reaction mixture until it reached a plateau where a steady state was observed, indicating the end of the reaction. Different pure and used vegetable oils were used in the study and it was observed that the plots of shear stress versus reaction time showed similar results. The results obtained were also able to tell if saponification took place. ${ }^{18}$

Clarks et al. ${ }^{19}$ obtained reproducible $\mathrm{pH}$ measurements that were used to monitor the transesterification reaction of canola oil using potassium hydroxide as a catalyst. The $\mathrm{pH}$ measurements were also related to the conversion of canola oil to biodiesel. The data obtained from the experiments were fitted to a kinetic model and the findings were the same as those found by other investigators. ${ }^{20}$ The results showed that the biodiesel formation process was characterized by an initial fast increase in $\mathrm{pH}$, followed by a gradual decrease until the $\mathrm{pH}$ remained constant, which showed the completion of the reaction. The change in $\mathrm{pH}$ was related to the dilution of $\mathrm{OH}^{-}$ions as the oil was converted to biodiesel, and not the depletion of $\mathrm{OH}^{-}$ because $\mathrm{OH}^{-}$ions are soluble in biodiesel but not in oil. The saponification was shown by a gradual increase in $\mathrm{pH}$ until it became constant. The amount of oil converted to biodiesel during the reaction $X_{(t)}$ was determined using Equation 1.

$$
\mathrm{X}(\mathrm{t})=\frac{10^{-(14-\text { peak } \mathrm{pH})}-10^{-(14-\text { peak } \mathrm{pH} \text { at time } \mathrm{t})}}{10^{-(14-\text { peak } \mathrm{pH})}-10^{-(14-\text { final expected } \mathrm{pH})}}
$$

These results show that $\mathrm{pH}$ measurements can be used successfully as a simple and cost-effective way to monitor the conversion of oil to biodiesel. The $\mathrm{pH}$ method of monitoring is simple to use; no special technical skills are needed to operate a $\mathrm{pH}$ meter. Compared to other monitoring equipment, like
NMR, GC, IR and GPC, pH meters are cost-effective and easily accessible.

In order to investigate the generality of $\mathrm{pH}$ measurements to monitor the progress of transesterification reactions, in the present study we have used sunflower oil and the non-conventional catalysts potassium and sodium carbonate. The solubility of carbonates in oil/biodiesel is not expected to be the same as hydroxides. Moreover, it is still unclear whether they can be considered as homogenous or heterogeneous with respect to dissolution in methanol. ${ }^{21}$ It is therefore of interest to compare the change of $\mathrm{pH}$ with time under hydroxide- and carbonatecatalyzed transesterification. A common practice which has been shown to speed up transesterification is the use of co-solvents, such as tetrahydrofuran (THF). ${ }^{22,23}$ In this study, we have used water, glycerol and gamma-valerolactone (GVL) as co-solvents to the methanol. Both water and glycerol are known to dissolve carbonates and GVL has been used successfully before as a blending fuel for biodiesel and was found not to have any effect on fuel properties. ${ }^{24}$ It is potentially greener and cheaper than THF as a co-solvent.

\section{Methods}

Transesterification reactions with methanol (Sigma Aldrich, HPLC grade) were carried out at $323 \mathrm{~K}$ and atmospheric pressure in batch reactors. Sunflower oil (Spar stores; an acid value of $0.07 \mathrm{mg} \mathrm{KOH} \mathrm{g}^{-1}$, molecular weight of $879.5 \mathrm{~g} \mathrm{~mol}^{-1}$ ) was used. The method validation reactions were carried out with a methanol to oil molar ratio of 12:1. ${ }^{21}$ All other reactions were carried out with methanol to oil ratios of $6: 1$, at the temperature of $323 \mathrm{~K}$, and a catalyst concentration of $1 \%$ (with respect to the weight of oil) of $\mathrm{K}_{2} \mathrm{CO}_{3}$ and $\mathrm{Na}_{2} \mathrm{CO}_{3}$. Each $\mathrm{pH}$ data point represents a single $\mathrm{pH}$ measurement.

\subsection{Method Validation Experiments}

In order to validate the use of $\mathrm{pH}$ to monitor the transesterification progress under carbonate-catalyzed conditions, the procedure by Arzamendi et al. ${ }^{21}$ was followed. In this experiment, the researchers used size exclusion chromatography (SEC) to monitor the reaction. In brief, the reactions were performed in a $50 \mathrm{~mL}$ two-necked glass flask, equipped with a reflux condenser and a magnetic stirrer, under atmospheric pressure. The reaction flask was placed in a water chamber kept at the desired temperature. To validate the use of $\mathrm{pH}$ to monitor the conversion of oil to biodiesel using potassium carbonate as a catalyst, the reactions were performed in a $50 \mathrm{~mL}$ batch reactor under the same conditions as the reference, ${ }^{21}$ i.e. 12:1 methanol to oil molar ratio and a temperature of $323 \mathrm{~K}$. The catalyst concentration used was $0.5 \% \mathrm{~K}_{2} \mathrm{CO}_{3}$ (with respect to the weight of oil).

Before starting the reaction, the required amount of carbonate was mixed with a small volume of methanol. The rest of the alcohol and sunflower oil was preheated to $323 \mathrm{~K}$ in the reactor. The start time of the reaction coincided with the addition of the catalyst to the heated reaction mixture.

\subsection{Co-solvent Experiments}

The procedure was the same as the method validation experiments except that the methanol to oil molar ratio was 6:1. The predetermined volume of co-solvent was added to the catalystcontaining methanol. The reaction started when this catalyst was added to the oil, which was already preheated to $323 \mathrm{~K}$.

\subsection{Computational Details}

First-principles density functional theory (DFT) calculations 
were performed using the Vienna Ab initio Simulation Package (VASP) ${ }^{25,26}$ a periodic plane-wave DFT code which includes the interactions between the core and valence electrons using the Project Augmented Wave (PAW) method. ${ }^{27}$ An energy cut-off of $500 \mathrm{eV}$ and Monkhorst-Pack ${ }^{28} \mathrm{k}$-point mesh of $3 \times 5 \times 5$ was used to sample the Brillouin zone of bulk $\mathrm{K}_{2} \mathrm{CO}_{3}$ and $\mathrm{Na}_{2} \mathrm{CO}_{3}$ materials. Geometry optimizations were performed based on the conjugate-gradient algorithm until the residual HellmannFeynman forces on all relaxed atoms reached $10^{-3} \mathrm{eV}^{-1}$. The electronic exchange-correlation potential was calculated using the Perdew-Burke-Ernzerhof (PBE) functional in the generalized gradient approximation (GGA). ${ }^{29}$

The METADISE code, ${ }^{30}$ which ensures the creation of surfaces with zero dipole moment perpendicular to the surface plane, was used to create the (001) surfaces of $\mathrm{Na}_{2} \mathrm{CO}_{3}$ and $\mathrm{K}_{2} \mathrm{CO}_{3}$. In each simulation cell, a vacuum region of $15 \AA$ deep was added perpendicular to the surface to avoid interactions between periodic slabs. The surface energy $\left(\gamma_{\mathrm{r}}\right)$, which quantifies the stability of the $\mathrm{Na}_{2} \mathrm{CO}_{3}(001)$ and $\mathrm{K}_{2} \mathrm{CO}_{3}(001)$ surfaces, was calculated using the equation:

$$
\gamma_{r}=\frac{\mathrm{E}_{\text {slab }}^{\text {relaxed }}-\mathrm{nE}_{\text {bulk }}}{2 \mathrm{~A}}
$$

where $E_{\text {slab }}^{\text {relaxed }}$ is the energy of the relaxed slab, $\mathrm{nE}_{\text {bulk }}$ is the energy of an equal number (n) to the bulk $\mathrm{Na}_{2} \mathrm{CO}_{3} / \mathrm{K}_{2} \mathrm{CO}_{3}$ species, and $\mathrm{A}$ is the surface area. The adsorption energy $\left(\mathrm{E}_{\mathrm{ads}}\right)$, which characterizes the strength of methanol or water adsorption, is calculated using the equation:

$$
\mathrm{E}_{\mathrm{ads}}=\mathrm{E}_{\text {mol }+ \text { surface }}-\left(\mathrm{E}_{\text {surface }}+\mathrm{E}_{\text {mol }}\right)
$$

where $E_{\text {mol+surface }}$ is the total energy of the relaxed adsorbate-substrate systems, $\mathrm{E}_{\text {surface }}$ is the total energy of the isolated surface, and $E_{\mathrm{mol}}$ is the total energy of the free methanol or water molecule. An exothermic adsorption process is characterized by a negative $E_{a d s}$, whereas an endothermic adsorption process is characterized by a positive value.

\section{Results and Discussions}

\section{1. $\mathrm{pH}$ Based Monitoring of the Carbonate-catalyzed Transesterification Reactions}

In this section, results for the carbonate-catalyzed transesterification reactions are presented, starting with the $\mathrm{pH}$ vs time plots, as these show subtle differences and similarities which may be useful in understanding the underlying chemistry. The fractional conversions obtained using Equation 1 are discussed next.

Figure 1 shows the changes in $\mathrm{pH}$ as the reaction progresses for the $\mathrm{Na}_{2} \mathrm{CO}_{3}$ and $\mathrm{K}_{2} \mathrm{CO}_{3}$-catalyzed reactions. For both reactions, there is an initial rapid increase in $\mathrm{pH}$ followed by a gradual decrease and finally levelling off of the graph. The initial increase has been attributed to the initial mixing or mass transfer of the oil and methanol. ${ }^{15}$ The gradual decrease in $\mathrm{pH}$ has been attributed to the conversion of oil to biodiesel, the so-called reaction stage of transesterification. The nearly constant $\mathrm{pH}$ at longer times indicates that the reaction is at an equilibrium stage. This behaviour is similar to what was observed by Clarks et al. ${ }^{19}$ when hydroxides were used as catalysts. The three phases have also been observed when using other monitoring techniques, like laser light ${ }^{15}$ and viscosity. ${ }^{17}$ The catalysts used in these investigations are both slightly soluble in methanol, ${ }^{10,21}$ with potassium carbonate being more soluble. The time taken to reach maximum $\mathrm{pH}$ was shorter in the $\mathrm{K}_{2} \mathrm{CO}_{3}$-catalyzed reaction $(7.5 \mathrm{~min}$ ) than in the $\mathrm{Na}_{2} \mathrm{CO}_{3}$-catalyzed reaction (12.5 min), which can be attributed to the higher solubility of the former in methanol, hence resulting in a shorter initial mixing period. The maximum $\mathrm{pH}$ values are 12.0 and 11.6 for the $\mathrm{K}_{2} \mathrm{CO}_{3}$ and $\mathrm{Na}_{2} \mathrm{CO}_{3}$-catalyzed reactions, respectively. The higher $\mathrm{pH}$ value for the $\mathrm{K}_{2} \mathrm{CO}_{3}$ catalyzed reaction could also be a result of its higher solubility in methanol.

The rate constants, $k_{2}$, for the reaction stage of both transesterification reactions were calculated assuming that at that stage the reaction proceeds by an irreversible second-order rate law. 19,20 These rate constants were calculated from plots of $1 /[\mathrm{OIL}]$ against time, where [OIL] is the time-dependent concentration of the sunflower oil. As shown in Table 1, as expected, the rate constant for the $\mathrm{K}_{2} \mathrm{CO}_{3}$-catalyzed reaction is found to be much higher than that of the $\mathrm{Na}_{2} \mathrm{CO}_{3}$-catalyzed reaction.

The oil-to-biodiesel fractional conversions, calculated using Equation 1, have been plotted in Fig. 2. It can be noted that, when using potassium carbonate as a catalyst, about $90 \%$ of the oil is converted to biodiesel within the first hour, while for sodium carbonate only about $65 \%$ is converted in the first hour. The faster rate of conversion in potassium carbonate is probably due to the more homogenous nature of the reaction as this catalyst is more soluble in methanol than the sodium carbonate. A comparison of the oil-to-biodiesel fractional conversions of the $\mathrm{K}_{2} \mathrm{CO}_{3}$-catalyzed sunflower oil transesterification reaction, monitored using $\mathrm{pH}$ and SEC, ${ }^{21}$ shows very similar results, as can be seen in Fig. 3. Thus, it can be concluded that the use of $\mathrm{pH}$ measurements in conjunction with Equation 1 can be extended to carbonate-based catalysts.

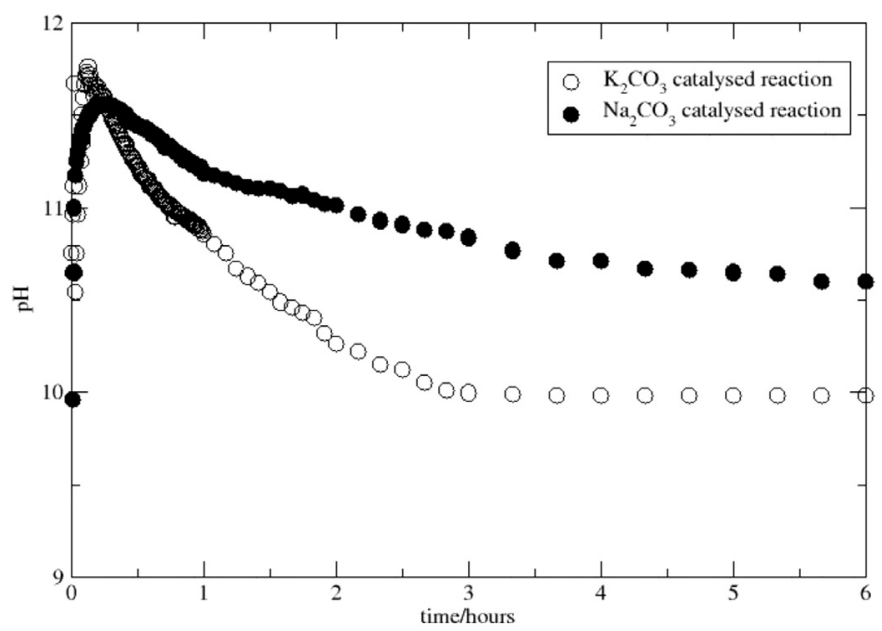

Figure 1 The change in $\mathrm{pH}$ as the reaction progresses for the reaction with $1 \% \mathrm{~K}_{2} \mathrm{CO}_{3}(\mathrm{O})$ and $1 \% \mathrm{Na}_{2} \mathrm{CO}_{3}(\mathrm{O})$ as catalysts.

Table 1 The rate constants $\left(k_{2}\right)$ for the reaction stage of the transesterification reaction at different reaction conditions.

\begin{tabular}{llcc}
\hline System & & $\begin{array}{c}\text { Rate constant }\left(\mathrm{k}_{2}\right) \\
\mathrm{L} \mathrm{mol}^{-1} \mathrm{~min}^{-1}\end{array}$ & $\mathrm{R}^{2}$ \\
\hline \multirow{2}{*}{ Catalyst type } & $1 \% \mathrm{~K}_{2} \mathrm{CO}_{3}$ & 0.2490 & 0.9573 \\
& $1 \% \mathrm{Na}_{2} \mathrm{CO}_{3}$ & 0.0614 & 0.9779 \\
Added water & $1 \% \mathrm{~K}_{2} \mathrm{CO}_{3}+0 \% \mathrm{H}_{2} \mathrm{O}$ & 0.2490 & 0.9573 \\
& $1 \% \mathrm{~K}_{2} \mathrm{CO}_{3}+0.16 \% \mathrm{H}_{2} \mathrm{O}$ & 3.4238 & 0.9953 \\
Added glycerol & $1 \% \mathrm{~K}_{2} \mathrm{CO}_{3}+0 \% \mathrm{Glycerol}$ & 0.2490 & 0.9573 \\
& $1 \% \mathrm{~K}_{2} \mathrm{CO}_{3}+1 \% \mathrm{Glycerol}$ & 0.0855 & 0.9940 \\
& $1 \% \mathrm{~K}_{2} \mathrm{CO}_{3}+2 \% \mathrm{Glycerol}$ & 0.1319 & 0.9772 \\
Added GVL & $1 \% \mathrm{~K}_{2} \mathrm{CO}_{3}+0 \% \mathrm{GVL}$ & 0.2490 & 0.9573 \\
& $1 \% \mathrm{~K}_{2} \mathrm{CO}_{3}+4 \% \mathrm{GVL}$ & 0.5674 & 0.9554 \\
& $1 \% \mathrm{~K}_{2} \mathrm{CO}_{3}+10 \% \mathrm{GVL}$ & 1.5968 & 0.9811 \\
\hline
\end{tabular}




\subsection{Effect of Adding Co-solvents Glycerol, Water and}

\section{Gamma-valerolactone (GVL)}

Adding a co-solvent to a reaction mixture speeds up the reaction rates (Table 1) as it enhances the miscibility of the oil and methanol phases, thereby generating a single-phase system. ${ }^{23}$ In this work three solvents were used as co-solvents.

The first co-solvent selected was water. Potassium carbonate is highly soluble in water, so the addition of small amounts of water can in theory speed up the rate of reaction by improving the dissolution of the catalyst, hence reducing the initial mass transfer limitations. Although water has been found to promote hydrolysis of triglycerides forming free fatty acids and, in the end, encouraging the saponification reaction, the transesterification reaction can tolerate small amounts of water. Added water should therefore not be excessive, whereas excess water can be removed easily after the reaction during the washing and drying of the biodiesel produced.

The second co-solvent used was glycerol as this is, in any case, a side product of transesterification. Although adding glycerol may be expected to slow down the reaction, in line with Le Chatelier's principle, because it is a by-product, it is also one of the few solvents that can completely dissolve sodium and potassium carbonates. It may, therefore, be expected that the presence of glycerol may lead to a more homogenous phase and hence speed up the reaction by reducing the crucial phase mixing time.

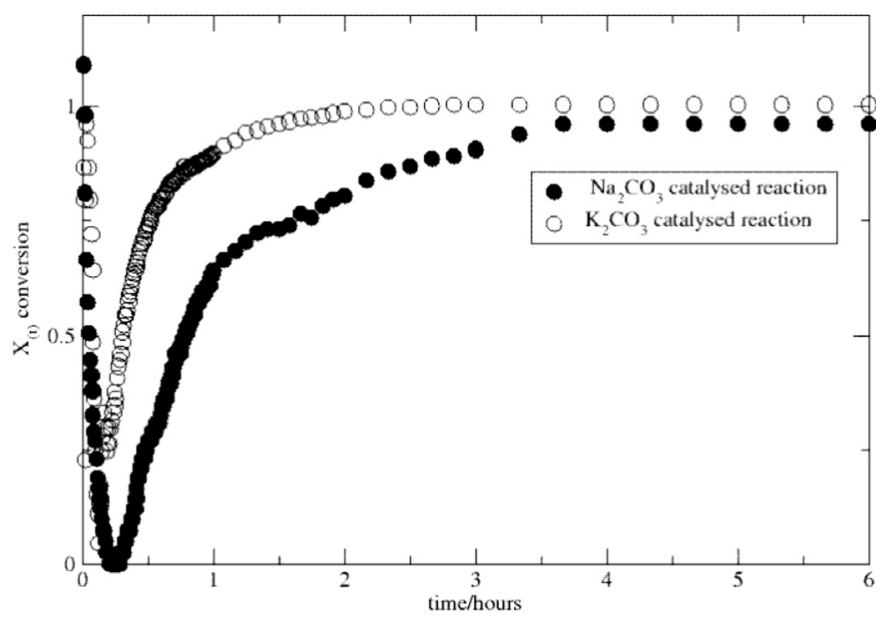

Figure 2 Conversion of sunflower oil to biodiesel using $\left(-\mathrm{Na}_{2} \mathrm{CO}_{3}\right.$ and (O) $\mathrm{K}_{2} \mathrm{CO}_{3}$ ) as catalysts.

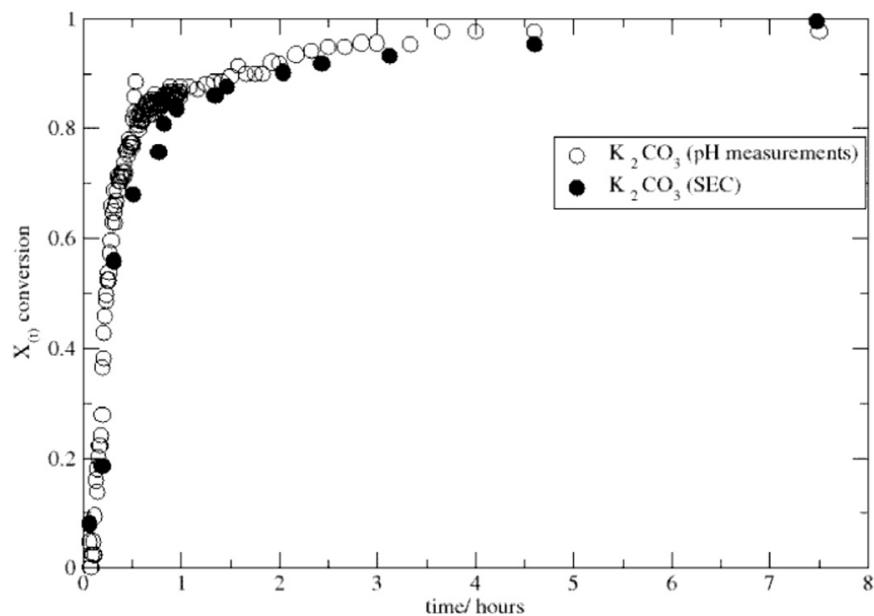

Figure 3 Graph of conversion of $\mathrm{K}_{2} \mathrm{CO}_{3}(\mathrm{O})$ obtained from this experiment and from Arzamendi et al. (৩) using size exclusion chromatography (SEC). ${ }^{21}$
The final solvent that was used in this work was gammavalerolactone (GVL). GVL has been found to have similar properties to ethanol. It has significant potential as a fuel itself and therefore can be blended with biodiesel. For this reason, it does not need to be removed from the biodiesel that is produced, ${ }^{24,31}$ thus reducing costs.

Figure 4 is the $\mathrm{pH}$ vs time plot for the $\mathrm{K}_{2} \mathrm{CO}_{3}$-catalyzed transesterification reaction with and without added water. The three stages, i.e. initial mixing, reaction stage and final equilibrium stages, are all present. When $40 \mu \mathrm{L}(0.16 \%)$ of water is added to the reaction mixture, the maximum $\mathrm{pH}$ reached is 12.8 and that occurs earlier than in pure methanol reactions. It can also be noted that where water is added, the $\mathrm{pH}$ decreases more rapidly after reaching the maximum value compared to the case of pure methanol. Water might help to improve the solubility of $\mathrm{K}_{2} \mathrm{CO}_{3}$ in methanol, hence increasing the reaction speed. It should be noted, however, that addition of more than $40 \mu \mathrm{L}$ resulted in a saponification reaction. ${ }^{32}$ As shown in Fig. 5, the addition of $40 \mu \mathrm{L}$ of water resulted in the complete conversion of oil to biodiesel within $60 \mathrm{~min}$ of the reaction. This behaviour is in agreement with the literature, 33,34 which states that small amounts of water can improve the catalytic activity of solid catalysts and biodiesel yields. In the presence of water, not only can methanol be deprotonated by $\mathrm{CO}_{3}{ }^{2-}$ but water can also be deprotonated to $\mathrm{OH}^{-}$, which is a stronger base to deprotonate methanol to form methoxide anions, which are the species that

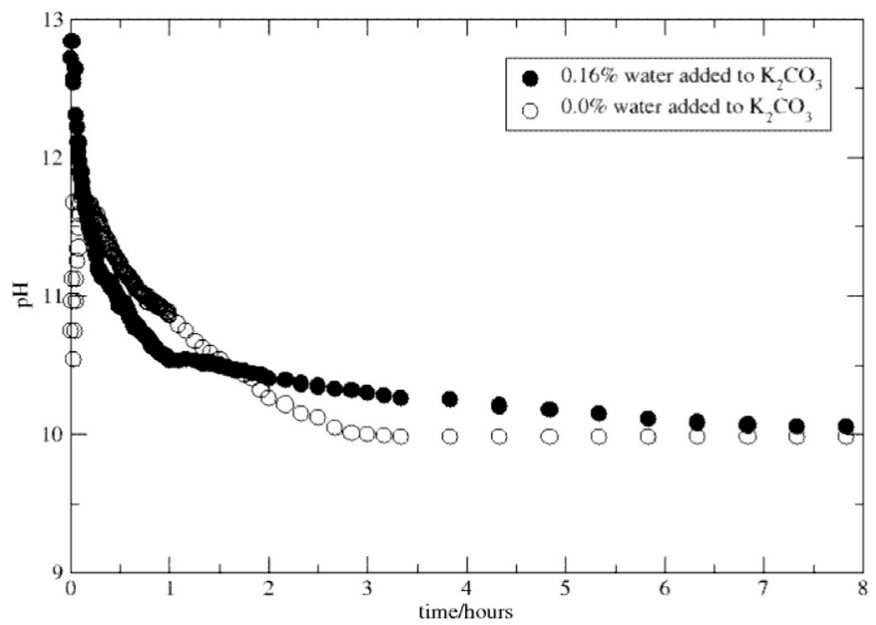

Figure 4 Effect of adding water to the $\mathrm{pH}$ the on $\mathrm{K}_{2} \mathrm{CO}_{3}$-catalyzed reaction.

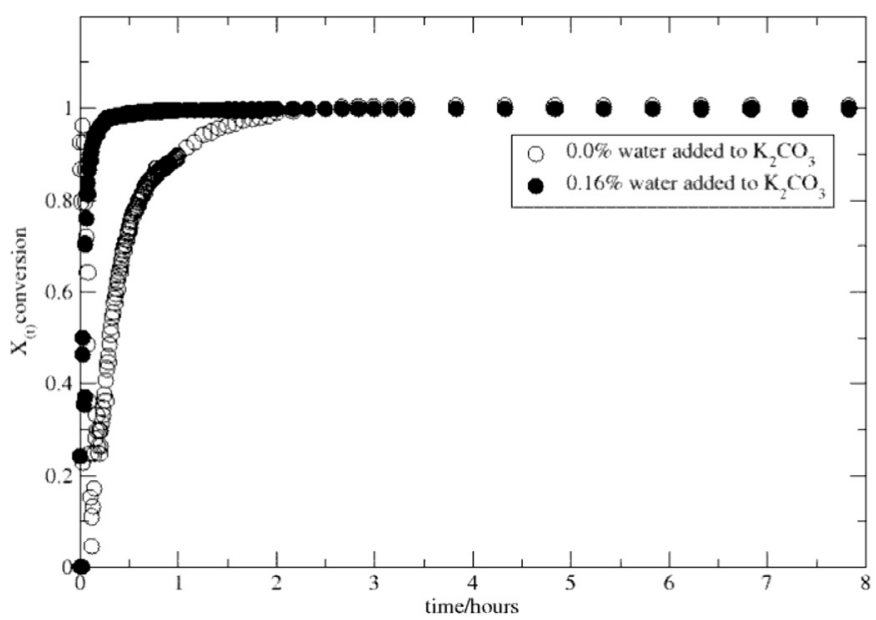

Figure 5 Effect of adding water on the conversion of oil to biodiesel on $1 \% \mathrm{~K}_{2} \mathrm{CO}_{3}$-catalyzed reaction. 
react with triglyceride to form corresponding fatty acid methyl esters (FAMEs) during the transesterification reaction. ${ }^{34}$ The dissolution of the catalyst in the presence of water increases the rate of the reaction, which is also supported by the rather high second-order rate constant (Table 1) for the case of added water.

As to glycerol, the $\mathrm{pH}$ vs time profiles (Fig. 6) also exhibit the three stages of initial mixing, reaction and equilibrium, as observed in the earlier plots. The maximum $\mathrm{pH}$ values were attained at $450 \mathrm{~s}$ ( $0 \%$ added glycerol), $90 \mathrm{~s}$ ( $1 \%$ added glycerol)

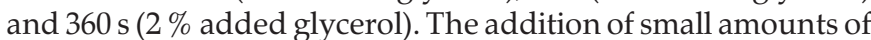
glycerol seems to shorten the time for the mixing stage, presumably due to increased solubility of the carbonate. However, as the amount of added glycerol increases, the mixing time again increases, this time probably due to increased viscosity of the reaction mixture. After the mixing stage, adding glycerol reduces the rate of the reaction $\left(\mathrm{k}_{2}\right.$ values are 0.0855 and $0.1319 \mathrm{~L} \mathrm{~mol}^{-1} \mathrm{~min}^{-1}$ for $1 \%$ and $2 \%$ added glycerol, respectively). One can assume that glycerol addition slowed the reaction, in agreement with Le Chatelier's principle, which is confirmed by the conversion vs time plot in Fig. 7. In the first $10 \mathrm{~min}$, glycerol does not affect the amount of oil converted to biodiesel. However, after $30 \mathrm{~min}$ the added glycerol appears to slow down the reaction, which can be rationalized by considering the fact that, at this point, the reaction is producing its own glycerol. The excess glycerol in the system might be causing glycerol-induced poisoning of the catalyst. ${ }^{35} \mathrm{It}$ is also clear from

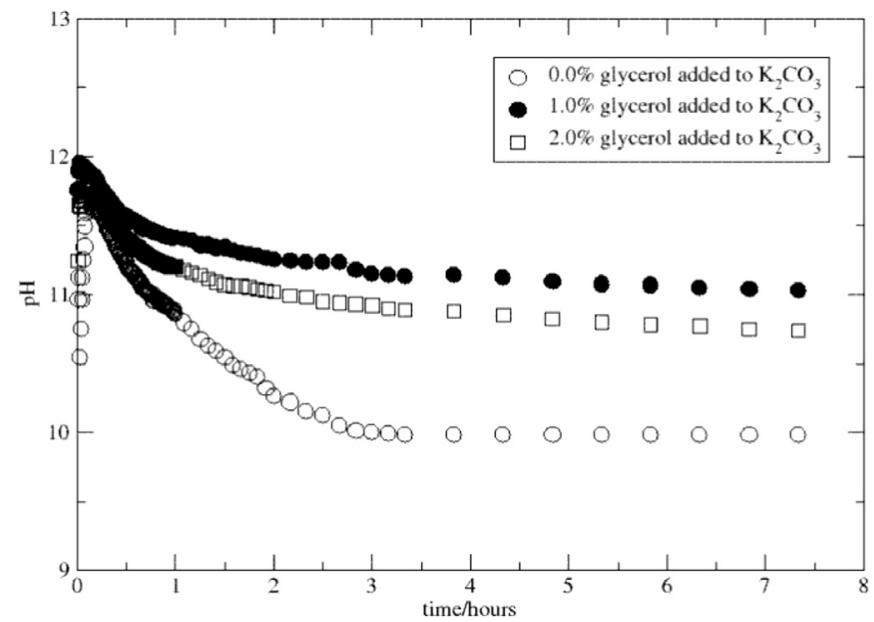

Figure $6 \mathrm{pH}$ time profile for $\mathrm{K}_{2} \mathrm{CO}_{3}$-catalyzed reaction with different amounts of added glycerol.

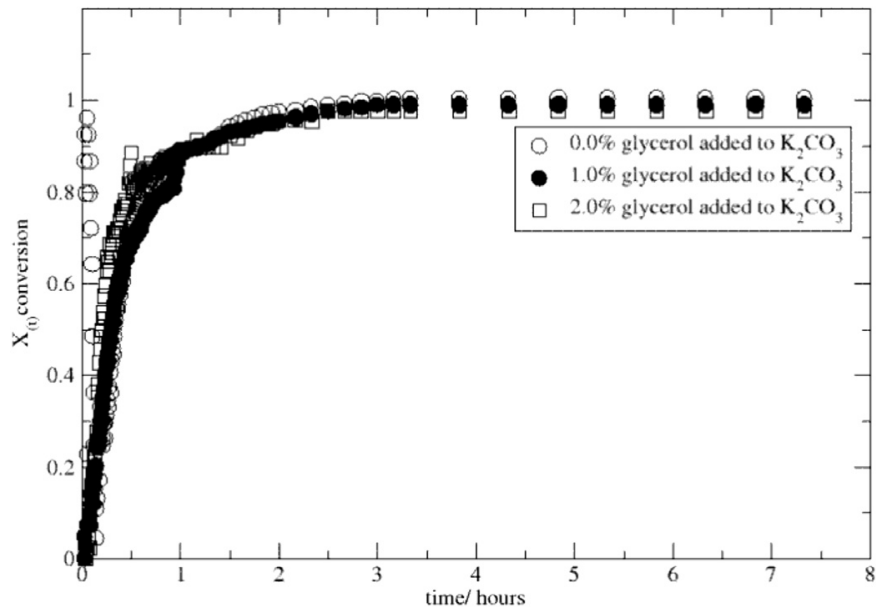

Figure 7 Oil conversions versus time profiles when adding glycerol as a co-solvent.
Fig. 7 that increasing the amount of glycerol has no significant effect on the final yield of the biodiesel.

The evolution of $\mathrm{pH}$ in the absence and presence of different amounts of added gamma-valerolactone to the potassium carbonate-catalyzed reactions is shown in Fig. 8. The three stages of transesterification are clearly visible. The $\mathrm{pH}$ versus time profile for the reaction with added GVL shows a rapid decrease compared to the one without GVL post the mixing stage. The mixing stage was prolonged when $4 \%$ of GVL was added compared to $10 \%$ GVL. The increase in the amount of GVL in the system might decrease the viscosity of oil and in turn, reduce the initial mass transfer limitations. It is clear from Fig. 9, that adding GVL increases the rate of formation of products. It can also be observed, that without GVL addition to the reactants, the yield after 1 hour was $89 \%$ but this increased to $98 \%$ after its addition.

\subsection{Computations of Methanol Adsorption on the $\mathrm{K}_{2} \mathrm{CO}_{3}$ and}

\section{$\mathrm{Na}_{2} \mathrm{CO}_{3}(001)$ Surfaces}

First-principles DFT calculations were carried out to characterize the adsorption behaviour of methanol at the (001) surface of $\mathrm{Na}_{2} \mathrm{CO}_{3}$ and $\mathrm{K}_{2} \mathrm{CO}_{3}$ catalysts. Although $\mathrm{Na}_{2} \mathrm{CO}_{3}$ and $\mathrm{K}_{2} \mathrm{CO}_{3}$ can crystallize in different phases at different temperature ranges, ${ }^{36-38}$ in the present study, we have considered only their most stable phases, ${ }^{39}$ i.e. $\mathrm{Na}_{2} \mathrm{CO}_{3}$ in the monoclinic phase with space group $\mathrm{C} 2 / \mathrm{m}$ (Fig. 10a) and the monoclinic phase of $\mathrm{K}_{2} \mathrm{CO}_{3}$

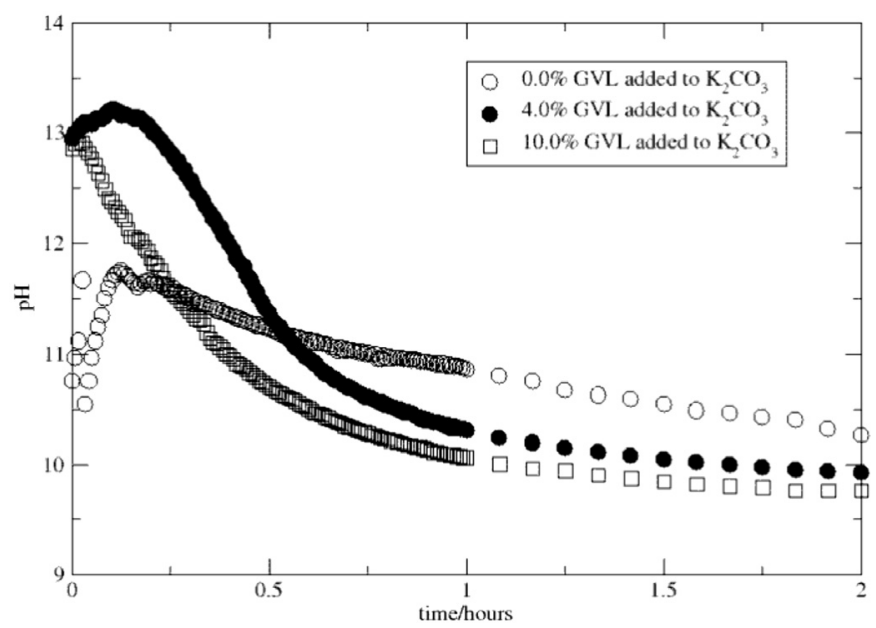

Figure 8 Change in $\mathrm{pH}$ when GVL was added to $\mathrm{K}_{2} \mathrm{CO}_{3}$-catalyzed reaction.

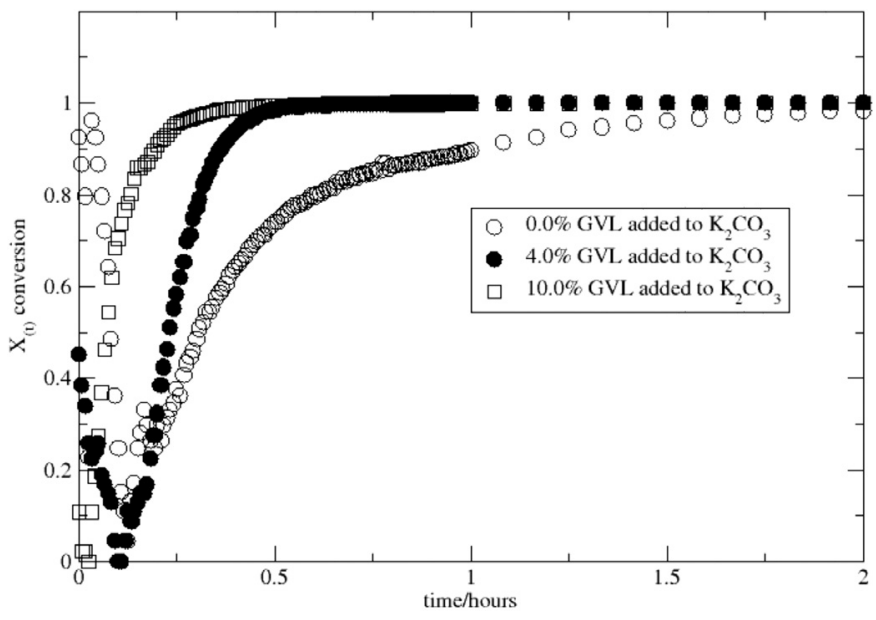

Figure 9 Effect of addition GVL as a co-solvent. 
(a) bulk $\mathrm{Na}_{2} \mathrm{CO}_{3}$

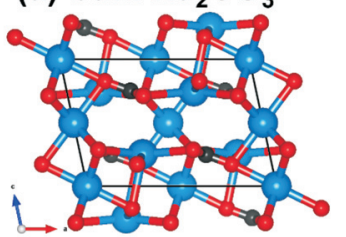

(c) $\mathrm{Na}_{2} \mathrm{CO}_{3}(001)$

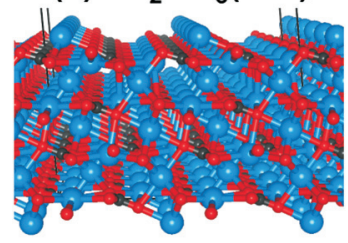

(b) bulk $\mathrm{K}_{2} \mathrm{CO}_{3}$

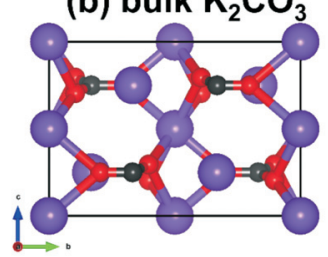

(d) $\mathrm{K}_{2} \mathrm{CO}_{3}(001)$

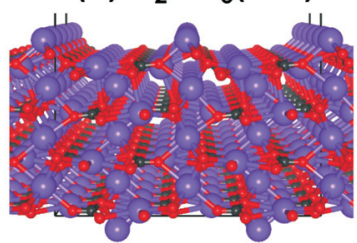

Figure 10 Optimized monoclinic crystal structures (a) $\mathrm{Na}_{2} \mathrm{CO}_{3}$ and (b) $\mathrm{K}_{2} \mathrm{CO}_{3}$; surface structures of (c) $\mathrm{Na}_{2} \mathrm{CO}_{3}$ (001) and (d) $\mathrm{K}_{2} \mathrm{CO}_{3}(001$ ). (Colour code: blue $=\mathrm{Na}$; purple $=\mathrm{K}$; black $=\mathrm{C}$; red = oxygen.)

with space group $\mathrm{P}_{1} / \mathrm{c}$ (Fig. 10b). The optimized structures of the $\mathrm{Na}_{2} \mathrm{CO}_{3}(001)$ and $\mathrm{K}_{2} \mathrm{CO}_{3}(001)$ surfaces used to characterize the adsorption energetics of methanol are shown in Fig. 10c,d). The surface energy, which characterizes the stability of a cleaved surface is calculated at 0.66 and $0.41 \mathrm{Jm}^{-2}$ for the $\mathrm{Na}_{2} \mathrm{CO}_{3}(001)$ and $\mathrm{K}_{2} \mathrm{CO}_{3}(001)$ surfaces, respectively.

To determine the preferred adsorption sites and lowestenergy adsorption configurations of methanol on the (001) surfaces, several different initial orientations were optimized without any symmetry constraints. Shown in Fig. 11a,b) are the optimized lowest-energy adsorption geometries of methanol on the $\mathrm{Na}_{2} \mathrm{CO}_{3}(001)$ and $\mathrm{K}_{2} \mathrm{CO}_{3}(001)$ surfaces, respectively. Methanol preferentially adsorbs at the $\mathrm{Na} / \mathrm{K}$ sites through its $\mathrm{O}$ atom, forming bridging bonds with the topmost and second layer $\mathrm{Na} / \mathrm{K}$ atoms. Stronger methanol adsorption is calculated the $\mathrm{Na}_{2} \mathrm{CO}_{3}$ (001) surface, with an adsorption energy of $-2.61 \mathrm{eV}$, than on the $\mathrm{K}_{2} \mathrm{CO}_{3}(001)$ surface, where it releases adsorption energy of $-1.29 \mathrm{eV}$. Consistent with stronger adsorption of methanol, a shorter O-Na distance of $2.505 \AA$ is calculated at $\mathrm{Na}_{2} \mathrm{CO}_{3}$ (001) surface compared to the O-K distance of $2.946 \AA$ at the $\mathrm{K}_{2} \mathrm{CO}_{3}(001)$ surface. The $\mathrm{O}-\mathrm{H}$ bond length of methanol at the $\mathrm{Na}_{2} \mathrm{CO}_{3}(001)$ and $\mathrm{K}_{2} \mathrm{CO}_{3}(001)$ surfaces is calculated at 1.022 and $1.011 \AA$, respectively, whereas the proton to surface oxygen distance is calculated at $1.642 \AA$ and $1.647 \AA$, respectively. When considered as a surfactant, the stronger binding of metha-

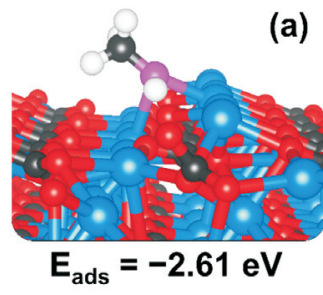

(c)

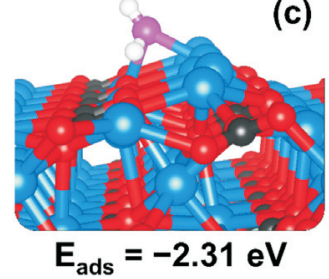

(b)

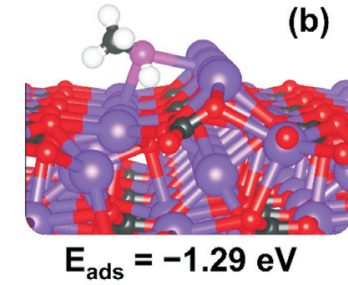

(d)

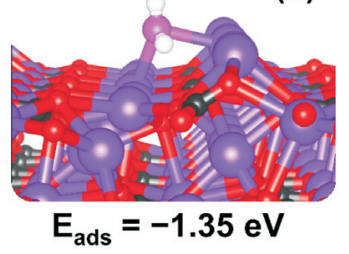

Figure 11 Optimized lowest-energy methanol and water adsorption structures on (a and c) $\mathrm{Na}_{2} \mathrm{CO}_{3}(001)$ and (b and d) $\mathrm{K}_{2} \mathrm{CO}_{3}(001)$ surfaces. (Colour code: blue $=\mathrm{Na}$; purple $=\mathrm{K}$; black $=\mathrm{C}$; red = oxygen; white = $\mathrm{H}$, pink $=\mathrm{O}_{\text {mol }}$ ) nol to the $\mathrm{Na}_{2} \mathrm{CO}_{3}(001)$ surface indicates that it stabilizes the surfaces of the $\mathrm{Na}_{2} \mathrm{CO}_{3}$ nanoparticles (grains) more than those of the $\mathrm{K}_{2} \mathrm{CO}_{3}$ particles, thereby protecting them better from dissolution.

However, as the methanol also contained a small number of water molecules - and water was also added to $\mathrm{K}_{2} \mathrm{CO}_{3}$ as a cosolvent-we have also characterized the adsorption energetics of water, to establish which species will compete successfully for the active cation sites. The adsorption of water led to adsorption energies of -2.31 and $-1.35 \mathrm{eV}$ at the $\mathrm{Na}_{2} \mathrm{CO}_{3}(001)$ and $\mathrm{K}_{2} \mathrm{CO}_{3}$ (001) surfaces, respectively (Fig. 11c,d). The stronger adsorption of water compared to methanol onto the $\mathrm{K}_{2} \mathrm{CO}_{3}(001)$ surface indicates that the water molecules will compete successfully with methanol for the $\mathrm{K}$ sites, and thus facilitate $\mathrm{K}_{2} \mathrm{CO}_{3}$ dissolution, which is in agreement with the experimental findings when water is added to the reaction mixture, as discussed above. In contrast, the stronger binding of methanol compared to water onto the $\mathrm{Na}_{2} \mathrm{CO}_{3}$ (001) surface suggests that the methanol species will compete successfully with water for the Na sites, and addition of water to the reaction mixture would, therefore, be unlikely to increase the rate of reaction in the $\mathrm{Na}_{2} \mathrm{CO}_{3}$-catalyzed transesterification reaction.

\section{Conclusions}

The progress of a carbonate-catalyzed transesterification reaction using methanol and sunflower oil has been monitored successfully by correlating the $\mathrm{pH}$ of the reaction mixture to the fractional conversion of oil to biodiesel. In general, the shapes of the time vs $\mathrm{pH}$ plots for carbonate-catalyzed reactions are similar to those obtained for the hydroxide-catalyzed reactions, with all three stages - reactant mixing, reaction stage and equilibrium stage - clearly distinct. The biodiesel yields under the potassium carbonate-catalyzed reaction as estimated from $\mathrm{pH}$ measurements show excellent agreement with those obtained using SEC. Application of the method to a study of the effect of the type of catalyst $-\mathrm{Na}_{2} \mathrm{CO}_{3}$ versus $\mathrm{K}_{2} \mathrm{CO}_{3}$ - as well as the addition of water, glycerol, and GVL on the $\mathrm{K}_{2} \mathrm{CO}_{3}$-catalyzed reaction rate has shown promising results. Owing to its higher solubility in methanol, potassium carbonate was found to be a better catalyst than sodium carbonate in terms of increasing the reaction rate. The addition of GVL was demonstrated to enhance the rate of the reaction, leading to increased biodiesel yield. Although a decrease in the reaction rate was observed for glycerol addition, it did not affect either the yield or the reaction time. The addition of small amounts of water was shown to have a positive effect on the reaction rate, but with an increase above $40 \mu \mathrm{L}$ facilitating saponification reactions. Atomistic DFT calculations reveal that water molecules will compete successfully with methanol for the $\mathrm{K}$ sites on the $\mathrm{K}_{2} \mathrm{CO}_{3}(001)$ surface, thus facilitating its dissolution and increasing the rate of reaction when water is added to the reaction mixture. In contrast, on the $\mathrm{Na}_{2} \mathrm{CO}_{3}(001)$ surface, methanol adsorbs preferentially, and the addition of water is therefore unlikely to increase the reaction rate for this catalyst.

\section{Acknowledgements}

The authors acknowledge the Royal Society and the UK Department for International Development, for funding under the Africa Capacity Building Initiative (ACBI), which has supported this research. We also like to thank BIUST for lab space and facilities that enabled us to do this work. NYD acknowledge the UK Engineering and Physical Sciences Research Council (EPSRC) for funding (Grant No. EP/S001395/1). This work has also used the computational facilities of the Advanced Research Computing at Cardiff (ARCCA) Division, Cardiff University, and 
HPC Wales. Information on the data that underpins the results presented here, including how to access them, can be found in the Cardiff University data catalogue at http://doi.org/ 10.17035/d.2020.0112138531

\section{${ }^{8}$ ORCID iDs}

M. Nyepetsi:

F. Mbaiwa:

O.A. Oyetunji :

N.Y. Dzade:

N.H. de Leeuw:

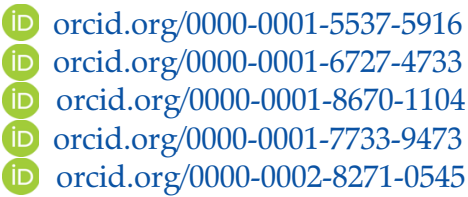

\section{References}

1 J. Van Gerpen, B. Shanks, R. Pruszko, D. Clements and G. Knothe, Biodiesel Production Technology: August 2002-January 2004, Golden, CO, USA, 2004. https://doi.org/10.2172/15008801

2 F. Ma and M.A. Hanna, Biodiesel production: a review, Bioresour. Technol., 1999, 70, 1-15. https://doi.org/10.1016/S0960-8524(99)00025-5

3 C. Öner and Ş. Altun, Biodiesel production from inedible animal tallow and an experimental investigation of its use as alternative fue in a direct injection diesel engine, Appl. Energy., 2009, 86, 2114-2120. https://doi.org/10.1016/j.apenergy.2009.01.005

4 G. Dwivedi and M.P. Sharma, Impact of antioxidant and metals on biodiesel stability - a review, J. Mater. Environ. Sci., 2014, 5, 1412-1425

5 E. Alptekin, M. Canakci, A.N. Ozsezen, A. Turkcan and H. Sanli, Using waste animal fat based biodiesels-bioethanol-diesel fuel blends in a di diesel engine, Fuel., 2015, 157, 245-254. https://doi.org/10.1016/j.fuel.2015.04.067

6 P.M. Ejikeme, I.D. Anyaogu, C.L. Ejikeme, N.P. Nwafor, C.A.C Egbuonu, K. Ukogu and J.A. Ibemesi, Catalysis in biodiesel production by transesterification process - an insight, E-Journal Chem., 2010, $7,1120-1132$. https://doi.org/10.1155/2010/689051

7 S.V. Ghadge and H. Raheman, Biodiesel production from mahua (Madhuca indica) oil having high free fatty acids, Biomass Bioenergy, 2005, 28, 601-605.

https://doi.org/10.1016/j.biombioe.2004.11.009

8 M. Ijaz, K.H. Bahtti, Z. Anwar, U.F. Dogar and M. Irshad, Production, optimization and quality assessment of biodiesel from Ricinus communis L. oil, J. Radiat. Res. Appl. Sci., 2016, 9, 1-5. https://doi.org/10.1016/j.jrras.2015.12.005

9 I.B. Banković-Ilić, I.J. Stojković, O.S. Stamenković, V.B. Veljković and Y.T. Hung, Waste animal fats as feedstocks for biodiesel production, Renew. Sustain. Energy Rev., 2014, 32, 238-254. https://doi.org/10.1016/j.rser.2014.01.038

10 C. Baroi, E.K. Yanful and M.A. Bergougnou, Biodiesel production from Jatropha curcas oil using potassium carbonate as an unsupported catalyst, Engineering, 2009, 7. https://doi.org/10.2202/1542-6580.2027

11 J.D. McCurry, GC Analysis of Total Fatty Acid Methyl Esters (FAME) and Methyl Linolenate in Biodiesel, Agilent Technologies, Inc., 2012. https://www.agilent.com/cs/library/applications/5991-0441EN.pdf

12 S.N. Csernica and J.T. Hsu, Simple and efficient method for the analysis of transesterification reaction mixtures for biodiesel production by reversed-phase high performance liquid chromatography, Energy Fuels, 2010, 24, 6131-6141. https://doi.org/10.1021/ef1009082

13 L.C. Meher, D. Vidya Sagar and S.N. Naik, Technical aspects of biodiesel production by transesterification - A review, Renew. Sustain Energy Rev., 2006, 10, 248-268. https://doi.org/10.1016/j.rser.2004.09.002

14 P. Hasuntree, V. Toomthong, S. Yoschoch and U. Thawornchaisit, The potential of restaurant trap grease as biodiesel feedstock, Songklanakarin J. Sci. Technol., 2011, 33, 525-530.

15 L.A.B. De Boni and I.N. Lima Da Silva, Monitoring the transesterification reaction with laser spectroscopy, Fuel Process. Technol., 2011, 92, 1001-1006. https://doi.org/10.1016/j.fuproc.2010.12.022

16 G. Knothe, Rapid monitoring of transesterification and assessing biodiesel fuel quality by near-infrared spectroscopy using a fiberoptic probe, J. Am. Oil Chem. Soc., 1999, 76, 795-800.

https://doi.org/10.1007/s11746-999-0068-5
17 N. Ellis, F. Guan, T. Chen and C. Poon, Monitoring biodiesel production (transesterification) using in situ viscometer, Chem. Eng. J., 2008, $138,200-206$. https://doi.org/10.1016/j.cej.2007.06.034

18 T. Rachmanto, D. Allanson, C. Matthews and I. Jenkinson, Monitoring of biodiesel transesterification process using impedance measurement, Int. J. Mater. Mech. Manuf., 2014, 2, 265-271. https://doi.org/10.7763/IJMMM.2014.V2.140

19 W.M. Clark, N.J. Medeiros, D.J. Boyd and J.R. Snell, Biodiesel transesterification kinetics monitored by $\mathrm{pH}$ measurement, Bioresour. Technol., 2013, 136, 771-774. https://doi.org/10.1016/j.biortech.2013.03.089

20 O.S. Stamenković, Z.B. Todorović, M.L. Lazić, V.B. Veljković and D.U. Skala, Kinetics of sunflower oil methanolysis at low temperatures, Bioresour. Technol., 2008, 99, 1131-1140. https://doi.org/10.1016/j.biortech.2007.02.028

21 G. Arzamendi, E. Arguiñarena, I. Campo, S. Zabala and L.M. Gandía, Alkaline and alkaline-earth metals compounds as catalysts for the methanolysis of sunflower oil, Catal. Today, 2008, 133-135, 305-313. https://doi.org/10.1016/j.cattod.2007.11.029

22 R. Sawangkeaw, K. Bunyakiat and S. Ngamprasertsith, Effect of co-solvents on production of biodiesel via transesterification in supercritical methanol, Green Chem., 2007, 9, 679-685. https://doi.org/10.1039/b614064e

23 M.D. Smith, X. Cheng, L. Petridis, B. Mostofian and J.C. Smith, Organosolv-water cosolvent phase separation on cellulose and its influence on the physical deconstruction of cellulose: a molecular dynamics analysis, Sci. Rep., 2017, 7, 1-9. https://doi.org/10.1038/s41598-017-15048-7

24 I.T. Horváth, H. Mehdi, V. Fábos, L. Boda and L.T. Mika, $\gamma$-Valerolactone - a sustainable liquid for energy and carbon-based chemicals, Green Chem., 2008, 10, 238-242. https://doi.org/10.1039/b712863k

25 G. Kresse and J. Hafner, Ab initio molecular dynamics for liquid metals, Phys. Rev. B., 1993, 47, 558-561. https://doi.org/10.1103/PhysRevB.47.558

26 G. Kresse and D. Joubert, From ultrasoft pseudopotentials to the projector augmented-wave method, Phys. Rev. B, 1999, 59, 1758-1775. https://doi.org/10.1103/PhysRevB.59.1758

27 P.E. Blöchl, Projector augmented-wave method, Phys. Rev. B., 1994, 50, 17953-17979. https://doi.org/10.1103/Phys.RevB.50.17953

28 J.D. Pack and H.J. Monkhorst, Special points for Brillouin-zone integrations, Phys. Rev. B., 1977, 16, 1748-1749. https://doi.org/10.1103/PhysRevB.16.1748

29 J.P. Perdew, K. Burke and M. Ernzerhof, Generalized gradient approximation made simple, Phys. Rev. Lett., 1997, 78, 1396-1396. https://doi.org/10.1103/PhysRevLett.78.1396

30 G.W. Watson, E.T. Kelsey, N.H. De Leeuw, D.J. Harris and S.C. Parker, Atomistic simulation of dislocations, surfaces and interfaces in $\mathrm{MgO}$, J. Chem. Soc. - Faraday Trans., 1996, 92, 433-438. https://doi.org/10.1039/ft9969200433

31 Á. Bereczky, K. Lukács, M. Farkas and S. Dóbé, Effect of $\gamma$-valerolactone blending on engine performance, combustion characteristics and exhaust emissions in a diesel engine, Nat. Resour., 2014, 5, 177-191. https://doi.org/10.4236/nr.2014.55017

32 E. Bikou, A. Louloudi and N. Papayannakos, The effect of water on the transesterification kinetics of cotton seed oil with ethanol, Chem. Eng. Technol., 1999, 22, 70-75.

https://doi.org/10.1002/(SICI)1521-4125(199901)22:1<70::AID-CEAT 70>3.0.CO;2-0

33 X. Liu, H. He, Y. Wang, S. Zhu and X. Piao, Transesterification of soybean oil to biodiesel using $\mathrm{CaO}$ as a solid base catalyst, Fuel, 2008, 87, 216-221.

https://doi.org/10.1016/j.fuel.2007.04.013

34 M. Zabeti, W.M.A. Wan Daud, M.K. Aroua, Activity of solid catalysts for biodiesel production: a review, Fuel Process. Technol., 2009, 90, 770-777.

https://doi.org/10.1016/j.fuproc.2009.03.010

35 Z.B. Todorović, D.Z. Troter, D.R. Đokić-Stojanović, A.V. Veličković, J.M. Avramović, O.S. Stamenković, L.M. Veselinović and V.B. Veljković, Optimization of $\mathrm{CaO}$-catalyzed sunflower oil methanolysis with crude biodiesel as a cosolvent, Fuel., 2019, 237, 903-910. https://doi.org/10.1016/j.fuel.2018.10.056 
36 M. Dusek, G. Chapuis, M. Meyer and V. Petricek, Sodium carbonate revisited, Acta Crystallogr. Sect. B, 2003, 356, 867-876. https://doi.org/10.1107/S0907444999000839

37 Y. Idemoto, J.W. Richardson, N. Koura, S. Kohara and C.-K. Loong, Crystal structure of $(\operatorname{LixK} 1-\mathrm{x}) 2 \mathrm{CO} 3(\mathrm{x}=0,0.43,0.5,0.62,1)$ by neutron powder diffraction analysis, J. Phys. Chem. Solids, 1998, 59, 363-376.

https://doi.org/10.1016/S0022-3697(97)00209-6

38 I.P. Swainson, M.T. Dove and M.J. Harris, Neutron powder diffrac- tion study of the ferroelastic phase transition and lattice melting in sodium carbonate, $\mathrm{Na}_{2} \mathrm{CO}_{3}$, J. Phys. Condens. Matter., 1995, 7, 4395-4417.

https://doi.org/10.1088/0953-8984/7/23/010

39 Y. Duan, B. Zhang, D.C. Sorescu and J.K. Johnson, CO 2 capture properties of $\mathrm{M}-\mathrm{C}-\mathrm{O}-\mathrm{H}(\mathrm{M} 1 / 4 \mathrm{Li}, \mathrm{Na}, \mathrm{K})$ systems: a combined density functional theory and lattice phonon dynamics study, J. Solid State Chem., 2011, 184, 304-311.

https://doi.org/10.1016/j.jssc.2010.12.005 